Historic, Archive Document

Do not assume content reflects current scientific knowledge, policies, or practices. 



\section{EXPERIMENT STATION}

TUSKEGEE NORMAL AND INDUSTRIAL INSTITUTE TUSKEGEE INSTITUTE, ALABAMA

\section{The Pickling and Curing of Meat in Hot Weather}

\section{Bulletin No. 24, 1912}

By George W. Carver, M. S. Agr. 
Experiment Station

Tuskegee Normal and Industrial Institute

TUSKEgEE INSTITUTE, ALABAma

\section{The Pickling and Curing of Meat in Hot Weather}

Bulletin No. 24, 1912

By George W. Carver, M. S. Agr. 



\section{FOREWORD}

I wish to gratefully acknowledge assistance in the preparation of this bulletin from the following sources, some of which I have copied word for word:

Farmers' Bulletins No. 183, U. S. Department of Agriculture.

Report of Swine Husbandry in the United Kingdom and Denmark.

The Rural World.

Pacific Dairy Review.

The Prairie Farmer.

The Farm and Home.

The Furrow.

The Tribune Farmer.

The American Agriculturist.

The Kansas Farmer.

The Southern Ruralist.

The Hearthstone.

Peerless Cook Book.

Home Cooking.

Common Sense Recipes.

Royal Baker and Pastry Book.

Mr. J. H. Washington, and Mrs. Worrell. 


\section{The Tuskedee Experiment Station}

\section{Board of Resenta}

Charles Coleman Thach, President..............Auburn, Alabama

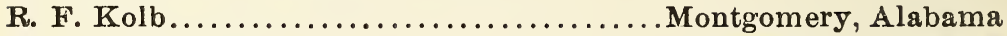

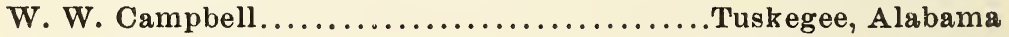

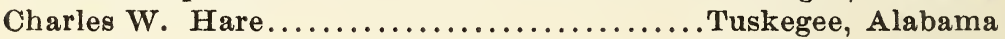

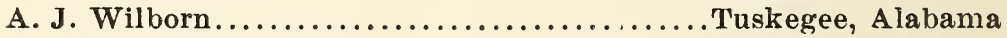
Booker T. Washington.............. Tuskegee Institute, Alabama Warren Logan..................Tuskegee Institute, Alabama

\section{Station Stafi}

G. W. Carver, M. S. Agr........................ Director George R. Bridgeforth.......... Director of Agricultural Industries Matthew Woods...Assistant to Director of Agricultural Industries

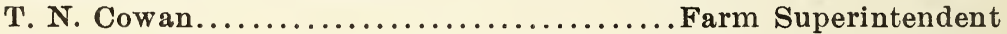
H. B. Jordon.... . . . .......Assistant to Farm Superintendent A. G. Chandler........................................

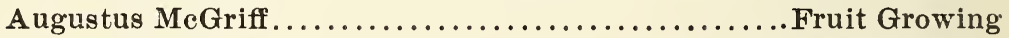

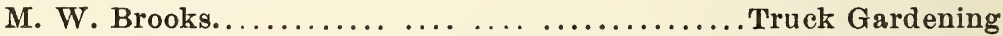
R. S. Pompey....................... Dairy Husbandry R. R. Robinson................. Swine Raising and Slaughtering

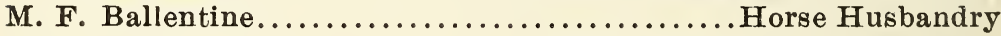

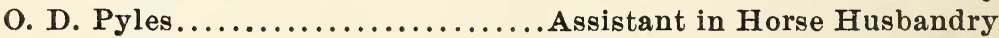

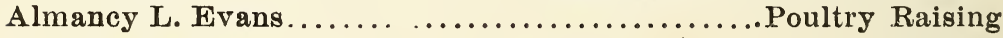

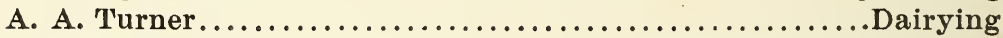

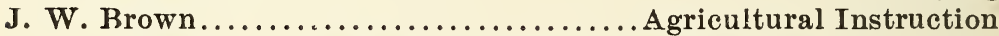
C. W. Greene......Assistant in Agricultural Instruction,

J. H. Bias Farmers' Institute and Short Course Work L. J. Watkins............Road Building and Construction Work

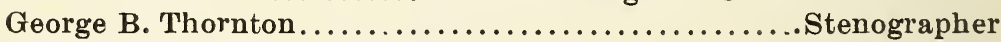
T. M. Campbell....... Demonstration and Farmers' Institute Work W. A. Tate.................. United States Demonstration Work 


\title{
The Pickling and Curing of Meat in Hot Weather
}

\author{
By G. W. Carver, M. S. Agr., Director
}

Many and varied are the methods of curing and otherwise preserving meat in the fall and winter months when the weather is cold enough to insure success.

All the methods examined were successful and some of superior merit, but the notion of killing and preserving meat in hot weather had scarcely been given a thought; "impossible" seemed to have been written across the face of any such proposition. However, two great problems demanding a solution seemed to be ever before us.

The entire South has been slow in the matter of pork production for the following reasons: First, the feedstuff for fattening hogs is especially plentiful in summer; the hogs grow off and fatten rapidly; they soon reach the killing point, and become a loss in dollars and cents, besides having other disadvantages whenever an attempt is made to carry them over till cold weather. Second, cholera. which rarely fails to make its more or less destructive appearance in the fall, seems to be especially partial to fat hogs.

I think possibly that these two things have done more to keep the South from being a great pork-raising center than all the others combined. With this situation before us, a pickling solution seemed the most feasible; so, therefore, we set about to find one.

A large number were found for the corning or pickling of beef, but those for pork were rather meager; but by taking those available in this and other countries, particularly those found in the United Kingdom of Great Britain, Ireland, Denmark, Holland, Scotland, England, and Canada, I was able to work out the following which has worked admirably with us.

\section{CORN CLUBS}

Nothing in recent years has stirred the South from center to circumference, as it were, as has the Demonstration movement and the boys' corn clubs. Boys 16 years old have been able to raise from 5, 19, 15, and 20 to $2243-4$ bushels (practically 225) per acre. This means more and better stock of all kinds, all of which are indications of greater prosperity.

The suggestions in this bulletin, if carefully carried out, should prove a fitting compliment to the Boys' Corn Club movement by 
the organization of Pig Clubs, and instead of buying most of our pork outside of our borders, sending millions of dollars from home, we shall be able to save these millions by supplying other sections of the country with choice pickled meat and bacon of superior quality.

\section{CAUTION}

Do not use dirty vessels of any kind-molasses, cottolene, and lard barrels are the best. They should be free from objectionable odors such as vinegar, kerosene, fish, etc., which might spoil the meat.

If meat has ever spoiled in a barrel or any other container, it must be thoroughly washed out and sterilized in some way until every trace of disagreeable odor disappears.

Do not put up meat that has begun to spoil, with the hope of saving it, as it will taint, to a greater or lesser degree, every piece of meat in the container.

\section{PREPARATION}

Kill and dress the meat in the usual manner, being extremely clean and tidy with every operation. Chill for 24 hours in a good refrigerator (if the weather is too hot to remove the animal heat without doing so) when left whole, and 12 hours when cut up ready for pickling.

\section{PROCESS}

After the vessels have been thoroughly cleaned, cover the bottom with salt. Rub each piece of meat vigorously with a handful of dry salt, packing the pieces in the vessel as tightly as possible. Sprinkle each layer liberally with salt. Fill with meat nearly to the top. Where the pieces are very large it is wise to cut the sides into two or three pieces and cut the hams and shoulders to the bone in several places with a sharp knife.

\section{PICKLING SOLUTIONS}

Of the several solutions given, the first one following has given us the greatest satisfaction, although you will note that there is very little essential difference in them.

\section{METHOD NO. 1.}

For every $100 \mathrm{lbs}$. of pork use $8 \mathrm{lbs}$. of salt, 4 lbs. of brown sugar or 6 lbs. of molasses, 2 ounces of baking soda, 4 ounces of saltpeter in hot weather, and 2 or none in cold weather.

Dissolve the above thoroughly in a sufficient amount of tepid water to cover the meat to a depth of four or five inches. Weigh down with a heavy stone. Do not let iron of any kind touch the brine, such as iron weights or nails in the board covers, as all such will impart a disagreeable flavor to the meat. The same is true with an unclean vessel of any kind.

The strength of the brine may be tested by dropping a fresh egg 
into it. If the egg floats upon the top, with two-thirds of its body out of the brine, it is strong enough; otherwise, more salt must be added.

\section{METHOD NO. 2.}

This method is highly recommended by the United States Department of Agriculture, Bulletin 183, and is as follows:

Rub each piece of meat with fine common salt, and pack closely in a barrel. Let stand over night. The next day weigh out $10 \mathrm{lbs}$. of salt and 2 ounces of saltpeter to each $100 \mathrm{lbs}$. of meat, and dissolve in 4 gallons of boiling water. Pour this brine over the meat when cold. Cover, and weigh down to keep it under the brine.

Meat will keep best if eut into pieces about six inches square. The pork should be kept in the brine till used.

METHOD NO. 3.

(For Sugar-cured Hams and Bacon)

This is a universal recipe, and has given satisfaction wherever used. Allow the hog to cool thoroughly before cutting. Trim hams and shoulders, and split the sides in two, lengthwise. Cover the bottom of the barrel with fine salt, and rub each piece of meat thoroughly with the salt. Pack tightly in a barrel, with hams on the bottom, shoulders next, and sides on top.

If the weather is sufficiently cool, allow the meat to stand for three days before putting on the pickling solution; in hot weather put it on at once. For each $100 \mathrm{lbs}$. of meat weigh out $8 \mathrm{lbs}$. of salt, $2 \mathrm{lbs}$. of brown sugar, and 2 ounces of saltpeter; 1 pint of molasses, 1 ounce of cayenne pepper, 1 ounce of black pepper berries (unground black pepper), 1 ounce of allspice berries, and 1 ounce of soda (baking soda). Dissolve all except the peppers and spice in the water; boil in an iron pot and skim as long as any sediment rises. When done add the peppers and the spice after having tied them up in a piece of thin cloth. Stir frequently with a wooden paddle until cool; then pour it over the meat.

In winter the brine need not be boiled. Weigh down as usual.

If bacon is desired the sides should remain in the pickle from four to six weeks; hams and shoulders from six to eight weeks; after which they are removed from the brine, washed off and smoked.

\section{ASHLAND HAMS}

Years ago what were known as Ashlaud hams were made at the old plantation of Henry Clay, which enjoyed a high reputation for their superior qualities and usually commanded the very highest prices. This recipe for curing was used by Mrs. Henry Clay for many years:

- For every ten hams of moderate size take 3 1-2 lbs. of salt, 1 lb. of saltpeter, and 2 lbs. brown sugar. Mix thoroughly and rub the hams therewith on every side. Then pack in a tight box or barrel, 
and place in a cool place for three weeks. Then put in a pickling tub or barrel and cover with brine of sufficient strength to float an egg. After remaining in this pickle about two weeks take out, rub lightly with fine salt and hang up in a well-ventilated place to dry for two or three days; after which transfer to the smoke-house, hang up about 3 or 4 inches apart and smoke carefully until they take a nice brown shade.

To keep during the summer or for shipping, sew up in heavy muslin, and limewash the outside. Add a little glue to the wash to cause it to adhere to covers. To make the hams still more secure for home use, put each one in a heavy paper sack, and tie tightly.

\section{AN OLD VIRGINIA RECIPE}

After chilling the meat thoroughly, make the brine as follows:

On the morning of the day the hogs are killed, for each $400 \mathrm{lbs}$. of meat, make the brine as follows: 20 gals. of rain water, $30 \mathrm{lbs}$. of salt, 8 ounces of baking soda, 10 lbs. of brown sugar, 1 gal. of molasses (use good molasses, not the adulterated kind). This fluid should be boiled and skimmed in the morning and left to cool in a shady place. When cool add 5 ounces of saltpeter. Dissolve the saltpeter in warm water and stir thoroughly.

The following morning cut up the hogs as usual, and pack in barrels. Put the sides of the meat or middling in the bottom, and the shoulders next, and the hams on top of these, all with the skin side down. Weight the meat down well, and pour the brine over until the meat is completely covered. Then cover the top of the barrel with some good thick covering that will prevent evaporation.

Look at the meat often enough to see that the brine has not evaporated so as to leave any meat exposed. If it should become exposed, more brine should be added. The meat can be left in the brine indefinitely, but if it is desired to smoke the meat, it should be taken out in about six weeks.

\section{CORNING BEEF NO. 1.}

Cut the beef up in small pieces, as nearly as possible of the same size, say five or six inches square. Weigh out the meat, and for every $100 \mathrm{lbs}$. allow $8 \mathrm{lbs}$. of salt. Sprinkle a layer of salt one-fourth of an inch thick on the bottom of the barrel; pack the cuts of meat in as closely as possible, making a layer five or six inches in thickness. Then put on a layer of salt, then a layer of meat in the same way until the barrel is as full as desired. Put a good layer of salt on top and let stand over night.

Now, for every $100 \mathrm{lbs}$. of meat add $4 \mathrm{lbs}$. of sugar, 2 ounces of baking soda, and 4 ounces of saltpeter dissolved in a gallon of tepid water. Three gallons more of water should be sufficient to cover this quantity. Weight down, and observe the same rules given for pork regarding the cleanliness of barrels, etc.

Watch the briue closely in hot weather, as it is likely to spoil at any time. If the brine appears ropy or does not drip from the 
fingers freely when immersed, it should be turned off, the meat washed, replaced in the barrel, and new brine added. The sugar or molasses causes this fermentation.

It requires from 28 to 40 days to secure thorough corning.

CORNING BEEF NO. 2

Cut and pack in a barrel the same as for No. 1, rubbing the salt mixture thoroughly into the meat. Let drain for a few hours. Prepare a brine as follows: For every $100 \mathrm{lbs}$. of meat use $7 \mathrm{lbs}$. of salt, 1 ounce each of saltpeter and cayenne pepper, 1 quart of molasses and 8 gallons of salt water. Boil and skim, and when cold pour ov the meat. The pepper should be mixed with the salt used in rubbing the ineat.

\section{CORNING BEEF NO. 3}

(Old English Recipe)

Cut up pieces as large as one desires; pack in a barrel or cask; make a brine as follows: 11-2 lbs. of salt to a gallon of water, 1 ounce saltpeter to $100 \mathrm{lbs}$. of beef, 1 tablespoonful of ground pepper to $100 \mathrm{lbs}$. of beef. Add salt and saltpeter to the water; bring to a boil, then skim; after which add the tablespoonful of pepper. Pour the brine on to the beef boiling hot and cover closely. Your meat will be good at any time. The hot brine closes the pores on the surface, preventing decay or getting too salt. It also retains the juice. If necessary scald the brine in the spring or make new brine, this time adding to the meat when cold.

\section{CANNING BEEF}

Here is an excellent way of canning beef to be used during the summer when fresh meats are scarce: Pot-roast the beef until tender, and season as for the table. Boil the liquor down until it will jelly when cold. Pick the meat into pieces small enough to go into cans easily. Scald the cans, fill with meat, pouring in stock enough to nearly fill the cans, on top pour just enough beef fat to cover the surface. Have ready a boiler of hot water, with a perforated board in the bottom. On this board set the cans of meat, far enough apart so they will not touch in boiling. Place rubber rings on the cans, laying covers on but not fastening. Fill the boiler with hot water until it comes to the necks of the cans. Cover the boiler tightly and boil steadily two hours, keeping the water to the necks of the jars. After boiling (not simmering) the required time, fasten the jars and set to cool, being careful to keep them out of a draft. Other meats, such as chicken, veal, etc., can be canned in the same way, also roasts, but they should be sliced before canning, liquid being poured over just the same as for pot roasts.

-Mrs. Eldon S. Cole, Stark, N. H.

METHOD No. 4.

(Sugar Cured Meat-Dry Curing)

The following most excellent recipe comes from the State of Kansas, and the writer has this to say about it: 
We think that any farmer who successfully uses the sugar method would never return to the dry-salt method, and that the curing of pork in this manner will solve the meat question for the year.

For every 1,000 lbs. of dressed meat, mix 1-2 bushel of salt, from 8 to 10 lbs. of dark brown sugar, $11-2$ lbs. of ground pepper. Then stir the mixture together thoroughly; take about one-fourth of a pound of saltpeter and dissolve in as little water as possible; add to the mixture.

Rub the meat well with this mixture; pack tightly in clean barrels; sprinkle the mixture liberally over each layer of meat. See that all cut surfaces, and especially the shank ends, are well salted. Pack as tightly in the box as possible, using the dry salt to fill all holes and vacant spaces. Put the joints in the bottom and the middlings on top. Use plenty of salt. If the weather is not cold enough to freeze the meat, it should lay in salt about two weeks. After it has taken sufficient salt, it should be taken up, brushed, and the remainder of the salt washed off in hot water. Hang, let drip, and smoke when dry.

\section{CAUTION RESPECTING THE BRINE}

1. It must be strong enough with salt to float a fresh egg, not on old stale one; an old egg will float in clear water.

2. Use no more saltpeter than is recommended, as it is a powerful astringent and $\mathrm{h}$ ardens the muscles of the meat, making it inferior. In cold weather use just one-half the amount or none.

3. In warm weather do not forget to examine the brine twice per week, and if it is inclined to become ropy, pour off, boil, and skim thoroughly; cool, and pour over the meat, or make a new brine altogether.

\section{CAUTION RESPECTING THE BARRELS OR CONTAINER}

1. As has been said before, the vessels in which you wish to pickle your meat must be clean.

2. Do not take meat from a container and immediately fill it again with fresh meat until it has been thoroughly cleansed and made sweet.

3. Do not attempt to use a ressel in which meat has spoiled until it has been thoroughly cleansed, with no trace of the taint left. See that it is well sterilized.

4. Do not use vessels for pork in which beef has been pickled, neither beef in vessels in which pork has been pickled.

\section{CAUTIONS RESPECTING THE MEAT}

1. Use only good, clean, sweet meat that has been carried through the chilling process.

2. If meat has begun to taint or sour, be it ever so little, do not attempt to pickle it, as it will continue to taint and spoil the entire contents of the container, 


\section{SMOKING}

Smoking adds much to the flavor and palatability of both pickled and dry cured meats, besides acting in some degree as a preservative and protection against insects.

\section{THE HOUSE}

Where much meat is to be smoked, a house 9 or 10 feet high is the most desirable. It should be built very tight so as to keep the smoke in. There should be several small ventilators at the top sufficient to insure a draft that will carry the smoke out slowly.

The meat should be hung 6 to 7 feet from the bottom of the house. Small amounts can be smoked in large dry goods boxes or even barrels.

It is wise to put a heavy piece of sheet metel directly over the fire, so that, if it should blaze up unduly, it. will not heat the meat directly under it.

\section{FUEL}

Hard wood of any kind is good for smoking meat but green maple or hickory, smothered with saw-dust of the same material, is the most desirable. Corn cobs make an excellent substitute for hard wood. Do not use pine or resinous woods of any kind; and if the highest quality of meat is desired, do not use soft wood of any kind, not even corn cobs, as they deposit a great deal of carbon or soot on the meat, making it black and unsightly, as well as injuring the flavor.

The smoking process should continue until the meat has a nice light, smoke brown which will require from three to four days and even longer if the fire is not kept. steadily going.

\section{AFTER PREPARATION}

If smoked meats are to be kept only for a short time and the weather is moderately cool, it can be safely kept right in the smokehouse by darkening it so as to exclude the flies and other insects. If they are to be kept a long time, wrap each piece, first in paper; then sew a piece of burlap or coarse cloth around it; dip in milk of lime so that every crack is closed by the whitewash, or make the following wash, which is known as yellow wash, the one used by most packers:

For $100 \mathrm{lbs}$. of ham or bacon take-

$$
\begin{aligned}
& 3.00 \mathrm{lbs} \text {. Barytes (barium sulphate) } \\
& 0.06 \mathrm{lbs} \text {. Glue } \\
& 0.08 \mathrm{lbs} \text {. Chrome yellow (lead chromate) } \\
& 0.04 \mathrm{lbs} \text {. Flour. }
\end{aligned}
$$

Mix the flour thoroughly with half a pail of water, being sure that every lump has been crushed. The chrome should be dissolved in another vessel holding a quart of water. Add this and the glue to 
the flour; bring the whole to a boil, adding the barytes slowly, stirring constantly. Let stand 24 hours. Apply with a brush; stir frequently when using, and cover every little crack.

After applying the above wash, allow the meat to hang for two or three weeks until thoroughly dry. Some take it down and bulk it with safety, but I prefer to hang it just far enough so that the pieces do not touch each other, and leave it so until ready to market or for consumption at home.

\section{DRY CURING METHODS}

In all dry curing methods the success depends almost wholly upon a cool temperature, either arificial or natural, and it is not wise to attempt them in warm weather.

\section{METHOD NO. 1 \\ (Sugar Cured Pork)}

This excellent recipe comes from Mrs. John Friedricks of LeMars, Iowa. Allow the pork to thoroughly cool before cutting. Carefully trim hams and shoulders, and split the sides in two, lengthwise. Sprinkle bottom of barrel with fine salt, and rub each piece of meat with salt.

Pack in ballel with hams on the bottom, shoulders next, and the sides on top. After three days cover the meat with brine made as follows: Water 8 gallons, salt $12 \mathrm{lbs}$. sugar $3 \mathrm{lbs}$, saltpeter 3 ounces.

I wish to suggest that, in hot weather, the brine must be put on within six hours, or the meat is likely to begin to sour next to the bone. Weight down in the usual manner.

\section{METHOD NO. 2}

(Sugar Cured-U. S. Department of Agriculture Bulletin 183.)

For each $100 \mathrm{lbs}$. of meat weigh out $5 \mathrm{lbs}$. of salt, 2 lbs. of granulated sugar, and 2 ounces of saltpeter. Mix them thoroughly.

Rub the meat once every three days with a third of the mixture. While the meat is curing it is best to have it packed in a barrel or tight box.

For convenience it is better to have two barrels, and to transfer the meat from one to the other each time it is rubbed. After the last rubbing the meat should lie in the barrel for a week or ten days when it will be cured and ready to smoke. To rure nicely it is best to have a cool and rather moist place in which to keep it.

\section{SOME FAVORITE DISHES FROM PORK}

While it is true that entirely too much pork is eaten in many sections of the country, it is equally true that the cousumption of pork will become less very slowly. So, therefore, it becomes necessary that more attention be given to its wholesome and appetizing: preparation, so that we may get rid of the nauseating, unpalatable, and death dealing morsals so often given out. 
Fried as some people fry it, in thick slices, about half done and swimming in grease, it is far from palatable or appetizing; but the thin crisp, brown slices are quite a different thing.

Again, many cooks fail in the preparation of pickled or salt meat of any kind simply because they do not freshen it enough. There are numerous ways of freshening pork, and each way gives it a distinct flavor, peculiar to the process.

\section{PICKLED OR SALIED PORK}

Soak the desired amount of meat over night in cold water (if very salty). Slice one-eighth of an inch thick. Put in a pan with about a quart of water; boil for an hour, or until the water has cooked out; allow the meat to brown, remove it and add one tablespoon of flour and a little pepper to the gravy; stir untilsmooth and brown (if you desire); add either milk or flour until thin enough. Serve over the meat or in separate gravy bowl.

\section{PORK STEW WITH VEGETABLES}

Take about 3 1-2 lbs. of pickled or salt pork (after freshening it properly. Cut into small pieces, say, 1 in. long and 1-2 in. thick. Add: 4 potatoes, 1 cup tomatoes, 2 carrots, 1-4 lb. finely shredded cabbage, 1 onion, 1 tablespoon rice, a few sprigs of parsley.

Boil the meat for 1 1-2 hours; add the vegetables, and cook slowly until all are thoroughly tender. Both red and black pepper may be used if desired.

\section{Method No. 1. Plain saUSAGE}

(U. S. Dept. of Agriculture, Bulletin 183)

Mix the fat and lean meat together in chopping. When fine enough spread out in a thin layer and season as follows: 1 ounce of pure fine salt, 1-2 ounce of ground black pepper, and 1-2 ounce of pure-leaf sase, rubbed fine to each 4 lbs. of meat. This will suit the taste of most persons.

The seasoning should be sprinkled thinly over the cut meat, and the meat again run through the cutter to mix the seasoning thoroughly. This method will give a more even mixing of the spices than can be obta!ned by working it with the hands.

If the sausage is intended for immediate use, it may be packed away in stone jars or crocks. It should be sliced for frying.

Many people stuff it into casings made from the small intestines of the hog. When this is done the intestines must be turned inside out and carefully cleaned.

A good substitute for casings may be had in narrow muslin sacks. These when filled should be $21-2$ or 3 in. in diameter and from 18 to 20 inches long. Stuff the sausage in tightly by hand, and hang in a cool place.

If the sausage is to be kept for some time, melted lard should be rubbed over the outside of the sack. This excludes the air. 
Sausage may be kept for some time in a large jar if a thin coat of lard is put over the top.

Mixed sausage may be made from pork and beef in almost any proportion. It is the custom on many farms to kill three or four hogs and a beef during the winter for the year's supply of meat. When this plan is followed a nice supply of sausage can be made from the trimmings.

\section{Method No. 2}

The sausage should not contain too much fat. A good proportion is $2 \mathrm{lbs}$. of lean pork, $1 \mathrm{lb}$. fat pork, and $1 \mathrm{lb}$. of lean beef. Chop together fine and season the same as pork sausage. Pack in jars, muslin sacks, or casings. Many people prefer this to clear pork sausage, as it is not so fat.

\section{Method No. 3. HIGHLY-SPICED SAUSAGE}

Those desiring special flavors in sausage will be pleased with the following:

To every $10 \mathrm{lbs}$. of ground meat add 4 even tablespoons of salt, 1 of black pepper, 1-2 tablespoon of cayenne pepper. Mix thoroughly. Then divide the meat into different portions; add pulverised sage, thyme, and summer savory to one portion in the proportion of 1 scant tablespoon each to 5 lbs of meat.

One tablespoon of ground celery will flavor another 5 lbs.

A like quantity of chopped parsley and onion juice will flavor a third. This should be used first.

Summer savory and onion is a combination that is liked by many.

Worcestershire sauce is good for a small quantity.

The author of the above keeps his sausage by making it into small cakes, partly frying, and packing it in stone jars, and covering over with lard.

\section{SUMMER SAUSAGE}

In the summer, when it is difficult to get fresh pork, very acceptable sausage can be made by taking very fat pickled or salt pork, grinding it with fresh beef, and seasoning the same as any other sausage.

\section{PICKLED PIG'S FEET}

Scald and scrape the feet. Clean; remove the toes, soak 12 hours in cold water; pack tightly in a jar, and cover with hot, spiced vinegar. The spice should be tied in a bag, covered tightly and set in a cool place until ready for use.

\section{BOILED PIGS' FEET No. 1. (Extra Fine)}

Wrap each pig's foot in a cotton bandage wound two or three times around it and well corded with twine. Boil for four hours in salted water if it is to be served at once or fried. Omit the salt if for pickling. 
BOILED PIG'S FEET NO. 2.

Clean feet thoroughly and cook until bones will slip out, using cold water if salted feet are used; hot water if fresh ones. Boil down, remove bones, and cut in two-inch lengths. Salt and pepper to taste, and pour with liquor into shallow dish. Let cool to jelly and cut in slices. Serve with garnish of cress, pepper grass, or parsley.

\section{BROILED PIG'S FEET}

Wash and clean six or eight feet. Place in a kettle with two onions, 2 carrots, 1 celery stalk, some thyme and lard. Cover with water, and cook for about 4 hours, or until tender; cut them in two, lengthwise; dip in butter; roll in bread crumbs, and broil from 10 to 15 minutes. Serve with mustard and mashed potatoes for breakfast or luncheon.

\section{HEAD CHEESE No. 1.}

Cut a hog's head into four pieces. Remove the brain, ears, snout, skin, and eyes. Cut off the fatest part for lard. Put the lean and bony parts to soak over night in cold water to extract the blood, etc. Wash carefully and put over the fire to boil, using water enough to cover it. Boil until the meat separates readily from the bone; then remove from the fire and pick out all the bones. Drain off the liquor, saving a part of it for future use. Chop the meat up finely with a chopping knife.

Return it to the kettle, and pour on enough liquor to cover the meat. Let it boil slowly for about half an hour. Season with salt and pepper to taste just before removing it from the fire.

Turn it into a shallow pan or dish; cover with a piece of cheese cloth, and put on a board with a weight to make it solid. When cold it should be sliced thin, and served without further cooking.

\section{HEAD CHEESE NO. 2.}

Clean the head as recommended in No. 1. Boil; separate the bones, and chop up in exactly the same manner. Divide into separate portions, and season in the same manner as Method 3 for highly spiced sausages. Pack in granite or earthenware dishes to harden. Sliced and eaten cold, there is nothing more toothsome.

\section{SCRAPPLE}

This highly appetizing dainty of our grandmothers is almost lost to this generation, but it is gradually coming back into favor, which it really deserves.

Make it exactly as head cheese. After the bones have been removed and the meat chopped, return it to the stove, pour the liquor over it; let come to a boil; stir in surfficient corn meal to make it the consistency of mush, boil slowly for an hour; pour into 
shallow dish to mold. When cold slice in strips about 1-2 an inch thick; roll in flour or dip in batter; fry a chicken brown in a little mixed lard and butter.

\section{TO COOK LIVER}

Put some lard or "pork fryings" in a skillet and add a little chopped onion and parsley. Put in the liver, sliced and seasoned with salt and pepper. Let it cook slowly until done, turning often. When cooked put in a warm oven. In a saucepan put one tablespoon of butter. When it bubbles add one tablespoon of flour. Stir until it is a good brown; then add 1 cup hot water, pepper, salt, the juice of half a lemon, or 1 tablespoon of vinegar, 1 tablespoon of capers, chopped pickle or nasturtium seeds. Put the liver on a hot platter; pour the sauce over it, allowing it to stand a few moments before sending it to the table.

\section{IIVER AND ONIONS}

Cut the liver in thin slices; pepper and salt; dip well into flour or meal; drop into hot fat; put on the cover, and let brown slowly. When brown on one side, turn, and have ready the desired quantity of onions you wish; cut into thin slices; pour over the top and return the cover. Add a spoonful of water if necessary; cook slowly until brown; stir the onions into the fat, and allow them to become slightly brown.

Remove the liver and onions to a hot platter; thicken a halfcup of rich milk with a tablespoon of flour; make a smooth, brown gravy; serve separately-do not pour over the liver.

\section{PIG'S FEET SALAD}

Cook the feet the same as for broiling; cut in pieces about two inches long and place in salad dish; pour over them a dressing made by mixing 1 tablespoon mustard, 3 tablespoons salad oil, 1-4 handful chopped parsley, the same quantity of chopped young onion tops, and four tablespoon vinegar. Add pepper and salt to taste. Serve for luncheon or picnic party.

\section{ROAST SPARE RIB}

Trim ribs nicaly and chop in 5 or 6 -inch lengths; place in roasting pan; dredge with flour; sprinkle with salt, pepper, and sage; add one cup of water, and roast, basting frequently until tender and brown; thicken the gravy with flour, and serve with baked apples or apple sauce. Mustard sauce is relished by some. Mashed potatoes and mashed turnips should be served in side dishes.

\section{FRIED SALT PORK WITH CREAM SAUCE}

Slice thin, fat salt pork; drop into boiling water in skillet and allow it to freshen for three minutes; pour off water; let drip; roll in flour; fry in skillet to a golden brown; lay on hot platter.

Into fat in skillet pour 1-2 pint of cream or rich milk; stir in 
flour and water to thicken; let come to a boil, and pour over pork. Serve with baked potatoes for breakfast.

\section{SUGAR ROAST OF HAM}

Soak the ham in cold water for 10 hours; entirely cover with water in kettle, and boli until tender; let drip; remove rind, and sprinkle with flour and coffee, sugar, or brown sugar (equal parts); stick full of cloves, about an inch apart, and roast until it is a coffee brown; garnish with parsley, and serve either hot or cold.

\section{PORK CHOPS WITH TOMATO SAUCE}

Dip the chops in melted butter or beaten eggs; roll in bread or cracker crumbs, and fry to a nice brown until well done; salt and pepper to taste; serve with tomato sauce in a separate dish.

\section{ROAST PORK}

The chine, or loin, and the spare ribs are the best pieces for roasting. Rub well with pepper, sage, salt, and flour; bake slowly until done and brown. Baste often; serve cold, as roast pork is more wholesome when eaten cold.

\section{BAKED HAM}

Soak a ham in cold water over night; trim it neatly; cover it all over with a thin crust of flour and water. Bake slowly eight hours; remove crust and skin; cover the $t \mathrm{p}$ with fine cracker crumbs slightly sweetened; place in the oven till the crumbs are brown; when cold eut in very thin slices, and serve.

\section{BREAKFAST BACON}

Slice the bacon very thin; cut off the rind, and hard part before slicing; fill a shallow pan with cold sweet potatoes sliced. Cover the potatoes with the bacon, and bake until the pork is crisp.

20. SOUSE

Take the gristly part of the pig's head, but not the fat, also the ears and feet; remove the hard part from the feet, scald or singe the hairs; soak in warm water, and scrape thoroughly; let them remain in salt and water for ten hours; scrape and clean again, and put them in a second time, in freshly salted water. This done with care they will be perfectly clean. Put them in a kettle and cover with cold water; skim when it begins to boil. Set back and let simmer until the bones slip out easily. Skim out the meat and remove the hard gristle, bones, and any superfluous fat; season with salt, pepper, and vinegar, and pack in stone jars. When hard cut in slices and brown in the oven. It may be served cold.

\section{HASLET STEW}

- Take equal parts of liver and lights; cut into small pieces. Add to this two are three kidneys, a melt or two, and a piece of jowl or fat from any portion of the hog to give it grease enough. Chop all 
the above into small pieces; pepper and salt to taste; boil slowly until thoroughly done. Serve hot with fried onions if desired.

\section{LIVER WORST}

Prepare the liver, lights, and all the other ingredients recommended for haslet stew (leaving out the kidneys); cook in the same way. When very tender remove from the fire, and when blood warm, mince very fine, picking out and discarding the skins and any hard portions. Season the same as for sausage. Mold and slice, or selve hot, with or without meat dressing, as you like.

\section{HAM AND VEAL SANDWICHES}

Simmer a knuckle of ham and about the same quantity of veal together in a small quantity of water until quite tender. Remove the bones, and mince together the same as for sausage (very fine). Spread like butter; add mustard, and cover with another slice of bread lightly buttered as for other sandwiches.

\section{PORK PIE}

Take five pounds of rather lean pork; cut in small pieces; put in a bettle with sufficient water to cover it; boil from two to three hours. For the crust use 11-2 cups of sour milk, 1-2 cup butter, or snow-drift lard, 1 teaspoon of salt and 1 teaspoon of soda. Butter a five-quart pan, and put in the crust. Do not roll it too thin. Put in your meat, pepper and salt to taste; pour in the water in which the meat was boiled; dredge in a spoonful of flour; roll a little lard in the top crust; wet the edge of your under crust before putting the top on; bake to a nice brown.

\section{ENGLISH HAM AND VEAL PIE}

This pie is said to be a favorite with many of Dickens' characters. Try two large veal cutlets from a leg of veal; take 1-2 pound or ham; cut the veal and ham in pieces about two inches square and place them in a saucepan with a quart of broth. When nearly done pour in a dish and let cool. Thicken the gravy with butter and flour; slice 1 large onion, 3 hard-boiled eggs; add a little sage and chopped parsley, pepper and salt, arrange meat and gravy in a dish, and pour gravy over; cover pie with puff paste, and ornament with fancy cut pieces of paste; make a hole on tor; finish cooking, and brown the crust.

\section{BROILED HAM AND EGGS}

Cut the ham in thin slices; take off the rind; wash the slices in cold water, and lay them on the gridiron over quick coals. Turn frequently, and they will soon be broiled. Take them upon a platter (previously warmed); butter and pepper the ham. Have ready on the fire a pan of boiling water from the tea-kettle; break into it as many eggs as you require for the meal, aud when the "white" is done, dip out each egg carefully with a spoon so as to keep it whole 
and set it on one of the slices of ham.

After all is arranged sprinkle pepper over each egg and serve.

\section{PORK AND BEANS}

Soak beans for a few hours in cold water; parboil for a few minutes; pour off the water; add hot water and a piece of pork the size you wish; simmer gently until tender; add a little salt if the meat was not salty enough, also a little pepper and a tablespoon of sugar if desired; pour in baking dish; place a piece of meat directly in the center, and bake to a rich brown.

\section{ROAST LEG OF PORK}

Choose a small leg of fine young pork; cut a slit in the knuckle with a sharp knife and fill the space with sage and onion chopped and a little pepper and salt. When half done score the skin in slices but do not cut deeper than the outer rind; return to the oven and cook until done and to a rich brown, basting frequently. Remove from the pan to a hot platter; dip as much of the grease as possible from the gravy; take a tablespoon of flour and mix with half a cup of rich milk; let the gravy come to a boil; stir in the milk and flour; let boil three or five minutes; serve in gravy dish.

\section{PoRk WITH potatoes (Very fine)}

Prepare a leg of pork in the same way as the preceding recipe; before returning to the oven, after scoring, have ready the required number of medium-sized sweet potatoes that have been peeled and parboiled until two-thirds done. When done lay the potatoes and the pork in the platter; garnish with sliced tomatoes, raw onions and sprigs of parsley; serve with gravy in boat as in the former recipe.

\section{ROAST PIG}

Take a young pig. After thoroughly cleaning it outside and inside, rinse it out with cold water into which a tablespoon of cooking soda has been dissolved; rinse again in cold water. Wipe dry the inside and outside. Prepare the following dressing: 1 cupful of crumbs, 1 small onion (chopped), 2 teaspoons powdered sage, 3 teaspoons melted butter, 1 saltspoon of salt, same of pepper, 1-2 nutmeg (grated), and the yolks of two eggs well beaten. Moisten with 1-2 cup of soup stock.

Stuff the pig in its original size and shape; place in a kneeling position, in a dripping pan; dredge with flour; pour a little hot, salted water in the pan; keep well basted. When it begins to smoke all over, rub every ten minutes with a rag dipped in melted butter; this will keep the skin from cracking.

Roast in a moderately steady oven for two hours. Place pig upon a hot platter; surround with parsley and blanched celery tops; place a green wreath around the neck and a sprig of celery or an apple in its mouth.

Skim and strain gravy; thicken with browned flour, boil up; 
add a glass of any good wine and the juice of one lemon. Serve in a gravy boat.

In carving, cut off the head first; split down the back; take off the hams and shoulders and separate the ribs.

31. CRACKLING, OR FATTY, BREAD

This is an old, ante-bellum recipe, much prized in the early settlement of this country and by our Pilgrim Fathers.

Make a batter the same as for egg bread, except that the eggs and shortening are left out. Into this batter stir from half a pint to a pint of well-tried-out cracklings that have been broken into small pieces. Salt more liberally than for ordinary bread; bake and serve with sweet milk.

\section{FATTY CORN "DODGER"}

Take a quart of corn meal and a pint of broken-up cracklings; salt liberally; mix with warm water; make up into two or three small dodgers, and bake in a quick oven. Serve with raw onions and a vegetable dinner.

\section{SAUSAGE AND SCRAMBLED EGGS}

Cut two cooked sausages into small pieces and warm them quickly in a frying pan; pour off the fat, and add 1 tablespoon of butter; when melted turn in six eggs slightly beaten with 6 tablespoons of cream; stir constantly until thick and smooth; add salt and pepper to taste, and serve at once.

\section{FRANK FURTERS}

Have the pan ready, full of boiling water; add as many wellcured sausages as it will hold; boil vigorously for ten or fifteen minutes. Serve with onion and rye bread.

35. KIDNEY STEW

Soak in cold water, scald, and remove the outsicie membrane; cut them through the edge to the center, removing the hard part; put them in a stew-pan with two bay or sassafras leaves, four cloves, four pepper corns, a teaspoon of salt, 1 onion, 2 tablespoons of vinegar, and water to cover. Simmer until tender. Brown 1 tablespoon of butter; add 1 tablespoon of flour. When mixed add 1 cup of the liquor; season with pepper, salt, and lemon juice. Pour this over the kidneys, and serve very hot.

36. HASH

1 cup of cold pork,

2 cups cold potatoes,

1 cold, boiled onion,

1 teaspoon mixed mustard,

1 teaspoon Worcestershire Sauce.

Chop the meat, potatoes, and onions quite fine; add the seasoning; melt 1 tablespoon butter in a spider; turn in the hash; cook slowly until brown. 


\section{SPANISH HAM MAND EGGS}

Cut stale bread into half-inch slices and soak until soft in 1 cup of milk mixed with 1 beaten egg. Fry to a delicate brown on a well buttered griddle; mix 1 cup of minced ham and one-third of a cup of soft bread crumbs with cream to moisten; heat it, and season with cayenne; spread this mixture on each slice; cook several eggs in water just below the boiling point until firm enough to keep their shape after removing the shell; put a whole egg on each slice, and serve at once.

\section{HAM OMELET}

Take 3 lbs. of ham well broiled and chopped very fine (like mince meat), 7 eggs, 4 tablespoons of rich milk, pepper and a little salt, 1 large spoonful of butter; beat together the eggs (white and yolks) with a few whirls of the beater; put in milk, and beat fast one minute; stir the ham in the eggs; then pour in a frying pan when the butter is heating, not hissing; shake briskly over the fire, slipping cake-turuer under it to prevent burning; in four minutes double it over in the middle, turn out in a hot dish, and serve.

\section{IRISH STEW}

Take $2 \mathrm{lbs}$. of pickled or fresh pork, $1 \mathrm{lb}$. of mutton or veal; cut all into small pieces (say, 1-2 inch thick); 8 potatoes, 4 turnips, 4 small onions; nearly 1 quart of water. The vegetables should be cut or sliced fine. Boil the ineat 1 hour. Put in the vegetables; add pepper and salt to taste, a stalk or two of blanched celery and a small bunch of parsley; simmer until the vegetables are very tender and the gravy thick; place in a dish, and serve hot.

\section{HEAD OHEESE NO. 2}

Take pig's head, coarse trimmings of skin, bits of fat, the heart, part of the liver, and bits of the cheaper cuts of beef; prepare and boil the same as for souse until thoroughly tender; chop slightly; pour in shallow crocks and press; see that the lean and fat are well intermingled so as to give it a fine marbled appearance when sliced (the lean meat should predominate); serve in slices, cold, with mustard if desired.

\section{BACON AND EGGS}

Cut bacon in thin slices and fry it. When bacon is done fry eggs in the same pan. Break each egg separately in a cup, then throw quickly into the pan. Lay fried egg on each slice of bacon and serve at once.

\section{BROILED HAM AND POACHED EgGB No. 2}

Cut slices of boiled ham of equal sizes; broil on a gridiron over a clear fire; lay on a hot dish; lay on each a poached egg neatly trimmed; garnish with parsley and serve. 


\section{PORK SALAD}

Take a small pork roast; cook and allow to cool. Cut in very small pieces or mince as you desire. Chop 1-4 a handful of parsley and the same amount of onions; cut 6 fresh gherkins and 6 sweet cucumber pickles into small discs; put all in a bowl with 1 small glass of olive oil and vinegar; salt and pepper to taste; mix thoroughly, and stir into the meat.

\section{PORK-CHOPS SMOTHERED IN ONIONS}

Let a rib accompany each cut of pork; salt and pepper to taste; dip in flour; cook slowly, with lid on; when nearly done take off lid and brown; turn; cover with a generous layer of sliced onions; return lid for a few minutes; stir the onions into the gravy, and allow all to brown lightly together; lay on warm platter; garnish with slices of raw onions, ripe tomatoes, and strips of cucumber sweet pickle.

\section{NOTE}

Salt pork may be made to taste almost as nice as fresh pork by cutting it in thin slices and soaking for a few hours in sour butter milk, clabber or sweet milk, butter milk and clabber being preferable. Soaking in sweet milk gives it a distinct flavor. 